\title{
Survey on Behavioral Finance Theory
}

\author{
Wan Yang \\ Capital University of Economics and Business, Beijing 100070, China \\ YvonneYeung0103@outlook.com
}

\begin{abstract}
Behavioral finance theory put psychology especially behavior science theory into the finance in order to use its pioneering view reexamine investment behavior in financial markets. And it will put forward unprecedented challenges to the traditional finance theory. Behavioral finance explain the motivations, research, and forecasts the development of financial markets from microcosmic individual behavior and the psychology produce this kind of behavior. In this paper, the author review the development history, the basic research of behavioral finance theory and the future research direction for detailed.
\end{abstract}

Keywords: Behavioral Finance; History of development; Prospect Theory.

\section{Introduction}

With the development of economic theory, the economic outlook and the suggestion of economic policy more and more get the attention of people. As economists' economic forecasting often appear errors, and some even exactly opposite to the actual situation. Therefore the economists are condemned by more and more people. In order to make the research results of economics more rationality, better fitting with real economic situation, the study of the behavioral finance theory arises at the historic moment.

Traditional economics is widely regarded as a kind of experimental science, most of the study of economics depend on all kinds of reasonable assumptions, and these assumptions are of great importance in the decision. However, nowadays more and more researchers began to try to use experimental methods to study economics, they tried to modify and validate all kinds of basic economic assumption which makes the study of economics more and more dependent on the experiment and a variety of data collection, thus it will become more credible. Most of these studies are rooted in two obvious distinguish but now synthesize together, that is cognitive psychologists' judgment and decision about people, and experimental economists experimental tests of economic theory. The modern behavioral finance derive from the overlapping of cognitive psychology and the modern finance. The significance of behavioral finance research is not only lies in the correction of standard finance, in terms of microcosmic, the analysis of investors' psychology not only can make themselves effectively avoid decision error, but also can formulate investment specific strategy from the psychological deviation of others; In terms of macroscopic, it involves in the effective of the stock market, and the question that asset prices reflect the intrinsic value or not.

\section{The development history of behavioral finance}

Behavioral finance cannot leave the development of economic psychology, can be traced back to more than 100 years ago. Mackay discussed the generation, development and burst of all kinds of financial bubbles in the financial markets and the resulting of fear and helpless in the book Extraordinary Popular Delusions and the Madness of Crowds in 1841 [1]. Lebon in the book The Crowd: A Study of The Popular Mind>discussed the application of crowd behavior in psychology, sociology, finance [2].

In 1936, John Maynard Keynes in the book The General going of Employment, Interest and Money point out the psychological factors which influence the investor's information processing and investment management process and put forward the "beauty Contest" in the stock market and "sky loft" Theory [3]. He thought: the value of stock depends on the long-term future benefits in theory, but because of long-term expectations under the uncertain conditions is very difficult and not accurate, so 
investors should be short-term forecasts. At the same time, he pointed out that investors are irrational, the trading process is full of "animal spirits", and investors' expectations determines the final price of the stock market.

Kahneman and Tversky have great influence on the development of behavioral finance. in 1979, in the paper Prospect: An analysis of decision under risk and put forward the complete Prospect theory, they put forward the complete prospect theory, which laid the foundation of the behavioral finance theory, and set a new milestone for the development of behavioral finance [4].Then, in 1982, Kahneman, Tversky and Slovic pointed out in The judgment under uncertainty: heuristics rules of thumb and deviation that individuals make decisions in uncertain circumstances, would violate the Bayesian Law or other related the theory of probability, and showed a systematic cognitive biases or empirical deviation.

Since the $1990 \mathrm{~s}$, the impaction of investor psychology factors on the asset pricing and portfolio investment decision become a focus in the study of behavioral finance. Shefrin and Statman put forward the famous Behavioral Asset Pricing Model (BAPM) and Behavioral Portfolio Theory (BPT) in 1994 and in 2000 successively [5, 6].In 2002, the United States, Daniel Kahneman of Princeton university and Vernon Smith of George mason university, won the Nobel Prize in economics. The Nobel committee think they create a new research field of behavioral economics and experimental economics, and it fully reflects the mainstream economists' recognition of behavioral finance.

\section{3. the foundation and developing direction Behavioral finance theory}

\subsection{Prospect Theory}

When to make decisions under conditions of uncertainty, the traditional financial scientists often use the expected utility theory or subjective expected utility theory, and they usually assume that investors are rational, markets are efficient and compliance to integrity axiom, justice axiom, alternative axiom and constancy axioms. But in the real stock market, the decision-making behavior of investors often violate these axioms. As a result, the financial economists widely absorb research achievement of psychology, experimental economics and behavioral economics, actively improve the traditional expected utility theory and seek alternative models. Originally expected utility function is concave, and people's attitude towards risk is the same. As shown in figure $1 \mathrm{a}$. In fact, people's attitude towards high risk and low risk are significantly different. In the face of low risk, such as buying insurance, they are risk aversion, but in the face of high risk, such as buying a lottery ticket, they become risk appetite. This is the famous "Friedman-Savage confusion". In order to solve this confusion, Friedman and Savage in 1948 put forward a new function form which is different from the initial expected function, there are both concave and convex in the graphics. The attitudes towards insurance is consistent with concave part, and the attitude toward the lottery is consistent with the convex part, as shown in figure $1 \mathrm{~b}$. Markowitz also studied this question and he pointed out that the inflection point of the utility function should be qualified in the "customary wealth" position, a narrow area, and the utility should be define by gains or losses, but not measured by the final wealth, as shown in figure $1 \mathrm{c}$.

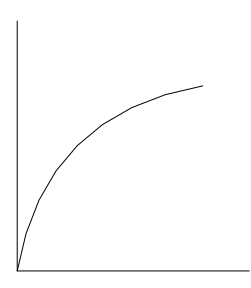

a)

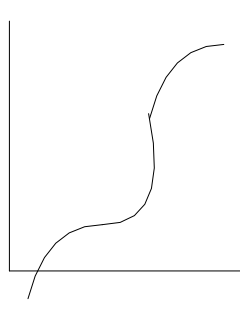

b)

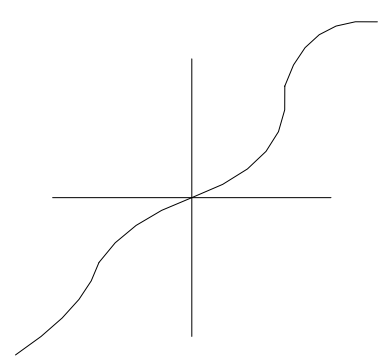

c)

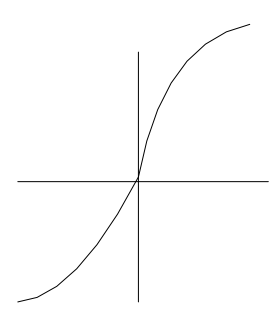

d)

Figure 1 Improvement model of utility theory and prospect theory model 
In 1979, on the basis of summarizing the predecessors' research, prospect theory, which is put forward by Kahneman and Tversky as shown in figure $1 \mathrm{~d}$, laid the foundation of the behavioral finance theory. The theory mainly includes: one is from the perspective of information processing to set up cognitive descriptive model in the individual risk decision-making process; another is Weighing Function and Value Function. At the same time, the prospect theory explains the financial market anomalies and think it comes down to Certainty effect, Reflection effect, and Isolation effect. Certainty effect refers to that compared with some probabilistic earnings, people will choose the events which yield is certain; Reflective effect shows that the risk aversion tendencies within the scope of income associated with the risk preference attitude within the scope of losses; Isolation effect is that even an information disclosure or not is not important for investment decisions, but people are still willing to wait for the publish of the information and to make a decision later.

\section{2 behavioral finance research paradigm}

Paradigm concepts are used to describe as the academic norms in a certain industry field researchers should follow, and it helps to solve the problem of study and which method to use. The premise of Traditional financial theory research is that investors is perfectly Rational, so it is also known as the "Rational Approach". But the premise of Behavioral finance theory research is all kinds of Psychological phenomenon of irrational investors, therefore it is also called "Psychological Approach", and its main research method experimental research method, research contents are the financial "anomalies", bounded rationality and limited arbitrage.

On the research methods, Behavioral finance theory is different from Normative and empirical research of the traditional financial theory. It mainly depends on a series of carefully designed experiments, and according to the result of experiment to reveal the law of human psychology and behavior, namely experimental economics. Its research model is that by design and simulation environment, to test one kind of phenomenon or behavior, and then observe the behavior of decision makers and get the analysis of test results, thereby verify the theory of economics. Smith, in 1982, established a standard research design and analysis system, and defined the steps that the economics experiment should follow, and he pointed out that each experiment are compose by environment, system and behavior the three main elements. There are five prerequisites should be meet when to Control environment and system in the environment variable: (1) the unsaturated, it refers to that people's desire for material wealth such as money is endless;(2) the salience, it refers to that the behavior of the individual and strategy determines the final result;(3) the objectivity, remain objective refers to the experimental process must keep objective and fair, the result is not be controlled by subjective cost or benefit of the participants;(4) privacy, to avoid mutual influence and the fairness of the result, each participant was only told his own rewards program;(5) parallelism, it refers to the conclusions through the experiment come into existence under the same conditions in the real world. George Smith improved people's understanding of the economic relationship in the process of mechanism design by economic experiments, which including the design of auction, public goods supply, flight schedules, government procurement, the state-owned assets and the design of the energy market.

\subsection{The forefront of behavioral finance}

The future development of behavioral finance are mainly concentrated in the following three aspects: first, the deep research on investor psychology, and the combination of psychology and economics research. The impact of Investors psychological on investment decisions is always one of the core propositions of behavioral finance, and the development of behavioral finance can't depart from the support of psychological research, it is an important significance to the development of behavioral finance with effectively utilizing psychology research results in the finance study. Second, explore new "anomalies" in market. Mining and research market "anomalies", can deepen people's understanding of financial markets. And it is an important approach to improve the behavioral finance theory. Third, perfect the behavioral portfolio theory and behavioral asset pricing model, and build a behavioral finance theory system. Behavioral portfolio theory and behavioral asset pricing model is an important means to research behavioral finance. But this model system has yet to be test of the 
market. The in-depth study of financial markets is an important way to improve quantitative analysis model, only in this way can make behavioral finance more vitality.

\section{Conclusion}

In this paper the author reviewed the development history, the theoretical basis and the future research direction of behavioral finance for detailed. The science of behavioral finance is that: first of all, it begins with axiom and seek theory which build on the axiom to explain the behavior of financial markets, it does not attempt to define the behavior of the "rational" or mark the decision as one-sided or flawed. On the contrary, it attempts to understand and predict the psychological decision-making system in the process of financial markets. Second, behavioral finance does not exclude the reasonable concept and principle of economics, but it pay attention to the use of psychology, behavioral science, human thinking Evolutionary and economics to improve financial decision making. Therefore, it makes the financial research is closer to reality. To sum up, there are many points worthy of research and development about behavioral finance, and with the combination of psychology, it will further development. At the same time, with the research and development of biology human behavior can be explain better, and it also provides a wider world for the development of behavioral finance.

\section{References}

[1] Mackay, C. (2012). Extraordinary popular delusions and the madness of crowds. Start Publishing LLC.

[2] Le Bon, G. (1897). The crowd: A study of the popular mind. Fischer.

[3] Keynes, J. M. (1937). The general theory of employment. The quarterly journal of economics, 209-223.

[4] Kahneman, D., \& Tversky, A. (1979). Prospect theory: An analysis of decision under risk. Econometrica: Journal of the econometric society, 263-291.

[5] Shefrin, H., \& Statman, M. (1994). Behavioral capital asset pricing theory. Journal of financial and quantitative analysis, 29(03), 323-349.

[6] Shefrin, H., \& Statman, M. (2000). Behavioral portfolio theory. Journal of financial and quantitative analysis, 35(02), 127-151. 